\title{
A FORTH LAW OF THERMODYNAMICS: SYNERGY INCREASES FREE ENERGY WHILE DECREASING ENTROPY
}

\author{
Klaus Jaffe ${ }^{1}$ \\ Universidad Simon Bolivar, Caracas, Venezuela
}

\section{ABSTRACT}

Synergy, emerges from synchronized reciprocal positive feedback loops between a network of diverse actors. For this process to proceed, compatible information from different sources synchronically coordinates the actions of the actors resulting in a nonlinear increase in the useful work or potential energy the system can manage. In contrast noise is produced when incompatible information is mixed. This synergy produced from the coordination of different agents achieves non-linear gains in free energy and in information (negentropy) that are greater than the sum of the parts. The final product of new synergies is an increase in individual autonomy of an organism that achieves increased emancipation from the environment with increases in productivity, efficiency, capacity for flexibility, self-regulation and self-control of behavior through a synchronized division of ever more specialized labor. Empirical examples that provide quantitative data for this phenomenon are presented. Results show that increases in free energy density require decreases in entropy density. This is proposed as a law of thermodynamics

Keywords: Entropy, Free energy, Synergy

\section{NOMENCLATURE}

$\begin{array}{ll}\Delta \mathrm{G} & \text { Change in Free Energy } \\ \Delta \mathrm{S} & \text { Change in Entropy } \\ \mathrm{M} & \text { Mass } \\ \mathrm{C} & \text { Complexity } \\ \mathrm{Cr} & \text { Redundant Complexity } \\ \mathrm{Co} & \text { Non-Redundant Complexity } \\ \mathrm{I} & \text { Information (Ir, Io) }\end{array}$

\section{INTRODUCTION}

Human knowledge has been advanced is different ways and with different methods, but during the last few centuries, the scientific method has proofed to be the most efficient and productive in advancing our understanding of the world and ourselves ${ }^{i}$. This method is often thought not to be applicable to certain realms of our knowledge such as humanities and many social sciences. However, complex system science has allowed us to extend the empirical scientific method to a much broader range of the social sciences ii. This exercise has opened opportunities to refocus on fundamental dynamical properties of complex social systems that where formerly regarded as not computable and dismissed as irreversible, far-from-equilibrium phenomena, that can not be a analyzed with thermodynamic sciences. Again, complex system sciences have allowed to tackle quantitatively issues that were regarded as diffuse, but important, such as synergy iii. Synergy has been found to be a very useful heuristic concept, both in natural and social sciences. Here I present a summary of novel findings that are relevant to thermodynamics and to an eventual Forth Law of Thermodynamics

\section{MATERIALS AND METHODS}

Revision of the existing literature using Google Scholar.

\section{RESULTS AND DISCUSSION}

One of the first scientific studies on synergy was performed by physiologist working on neuro-muscular interactions ${ }^{\text {iv }}$. This is the earliest scientific reference to synergy I could find. Then researchers introduced the concept into mainstream physics ${ }^{\mathrm{v}}$. At the same time, engineering started to

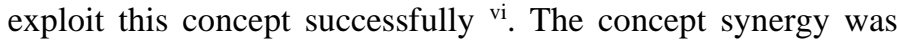
thus established as a phenomenon that emerged in complex open system and had non-linear properties in increasing the output variable of a process exponentially instead of geometrically. With advances in irreversible thermodynamics applied to open systems, as contrasted with classical equilibrium thermodynamics that apply to closed systems, we can group dynamic phenomena of open systems in at least four categories. I will refer to them as: Dissipation, Aggregation, Equilibration and Synergisation.

Dissipation refers to processes where energy and entropy is released by the system. A classical example is combustion, where a low entropy material, such as wood, is transformed into a high entropy mix of gases and heat. Here, G decreases as less wood will be available, and S increases as the entropy of the gas mix will be higher than that of the wood that originated them though combustion.

Aggregation occurs when resources are accumulated, such as in warehouses, or armies expand the territory of a nation, sediments accumulate of the bottom of a dam, or wealth in the stock-market. Here, both S and G increase, as more produces larger possibilities for work and larger possible arrangements between the parts.

Equilibration or drifting to equilibrium occurs when a system is not disturbed and natural forces act to minimize both $\mathrm{S}$ and $\mathrm{G}$. A classical example is crystallization, where a high entropy salt solution settles as a crystal, reducing $S$ and $G$ in the system. 
Synergization is the process where $\mathrm{S}$ production is reduced or delayed and $\mathrm{G}$ is increased due to a clever use of constrained border parameters. For example, a cannon ball placed upon a heap of fire powder will hardly move when the powder is burned. But if the fire powder is placed into a cannon with a cannon ball on top, the work produced by the flying cannon ball after the explosive burning of the constrained powder is very large indeed. That is, the cannon produces work (G) through a devise that achieves a reduction of S. But once the explosion has occurred, the energy of the explosion is dissipated. Thus, $S$ is reduced only if the appropriate time window is taken into account. It seems then that a Law of Thermodynamics exist, where the more border constraints, information, or structures defining the system, are present, the less Entropy (S) the system has, and the more Work (G) a system can produce. Life can then be defined thermodynamically as an open self-reproducing multicomponent synergistic system (see also autopoiesis vii ).

A summary of the differences between these four processes that might occur in open systems is given in Table 1.

TABLE 1: PROCESSES THAT MIGHT OCCUR IN OPEN SYSTEMS

\begin{tabular}{|c|c|c|c|c|}
\hline Name & $\boldsymbol{\Delta G}$ & $\boldsymbol{\Delta S}$ & Process & Example \\
Dissipation & - & + & $\begin{array}{c}\text { Combustion } \\
\text { War }\end{array}$ & $\begin{array}{c}\text { Engine } \\
\text { Loosing army }\end{array}$ \\
\hline Aggregation & + & + & $\begin{array}{c}\text { War } \\
\text { Stock-Market }\end{array}$ & $\begin{array}{c}\text { Winning army } \\
\text { Broker }\end{array}$ \\
\hline Equilibration & - & - & Crystallization & Salt Solution \\
\hline Synergisation & + & - & Life & Organism \\
\hline
\end{tabular}

Both, $\Delta \mathrm{G}$ and $\Delta \mathrm{S}$ can be measured and quantified. Table 2 presents the different systems where quantitative data of a synergistic process have been published. In all of them $\Delta G$ increased and and $\Delta \mathrm{S}$ decreased, although the way these quantities were measured varied. The references for the data presented are given in viii.

TABLE 2: SYNERGISTIC PROCESSES IN OPEN SYSTEM WHERE $\triangle$ G and $\triangle S$ HAVE BEEN QUANTIFIED

\begin{tabular}{|c|c|c|}
\hline System & Entropy estimate & $\begin{array}{c}\text { Free Energy } \\
\text { estimate }\end{array}$ \\
\hline Ants and Termites & Social complexity & Energy consumption \\
\hline Human Cities & Size as complexity & $\begin{array}{c}\text { Electricity } \\
\text { consumption }\end{array}$ \\
\hline Humans & Scientific development & $\begin{array}{c}\text { Economic } \\
\text { development }\end{array}$ \\
\hline Social Simulations & Division of labor & Economic efficiency \\
\hline Ant Anatomy & Brain complexity & Polymorphism, Colony \\
\hline Literary Texts & Text entropy & Literary impact (NP) \\
\hline Music & MIDI entropy & Popularity \\
\hline $\begin{array}{c}\text { Human } \\
\text { Organizations }\end{array}$ & $\begin{array}{l}\text { Organizational } \\
\text { structure }\end{array}$ & $\begin{array}{l}\text { Functional } \\
\text { performance }\end{array}$ \\
\hline
\end{tabular}

We have now an instrument to recognize synergy when it is present. Using this tool we can identify features present in all situations where synergy has been identified. These are: Open systems that harvest energy and negentropy fluxes in the environment, where Diversity, Cohesion, Synchrony and Complementarity occur between the parts of the system, constraining border conditions $(S)$ to increase the potential to do work $(\mathbf{G})$. The constrains of the border condition can be measured as information or complexity. When these open systems self-reproduce we have life.

Analogous conclusions have been presented by several other authors. I just want to highlight two: the concept of Autopoieses by Humberto Maturana and the Forth Law of Thermodynamics by Stuart Kauffman ${ }^{\text {ix }}$.

\section{CONCLUSION}

A synergistic open system increases the production of work only with more non-reduntant border constraints (i.e. information, structure or complexity) that reduce its entropy. A therodynamic law seems to be that increases in $\mathrm{G}$ density require decreases in $\mathrm{S}$ density: $\Delta \mathrm{G}=\mathrm{F}(\Delta \mathrm{S})$.

Life can then be defined as a self reproducing synergistic system.

\section{ACKNOWLEDGEMENTS}

Thanks to Ram Poudel for the motivation to write this note.

\section{REFERENCES}

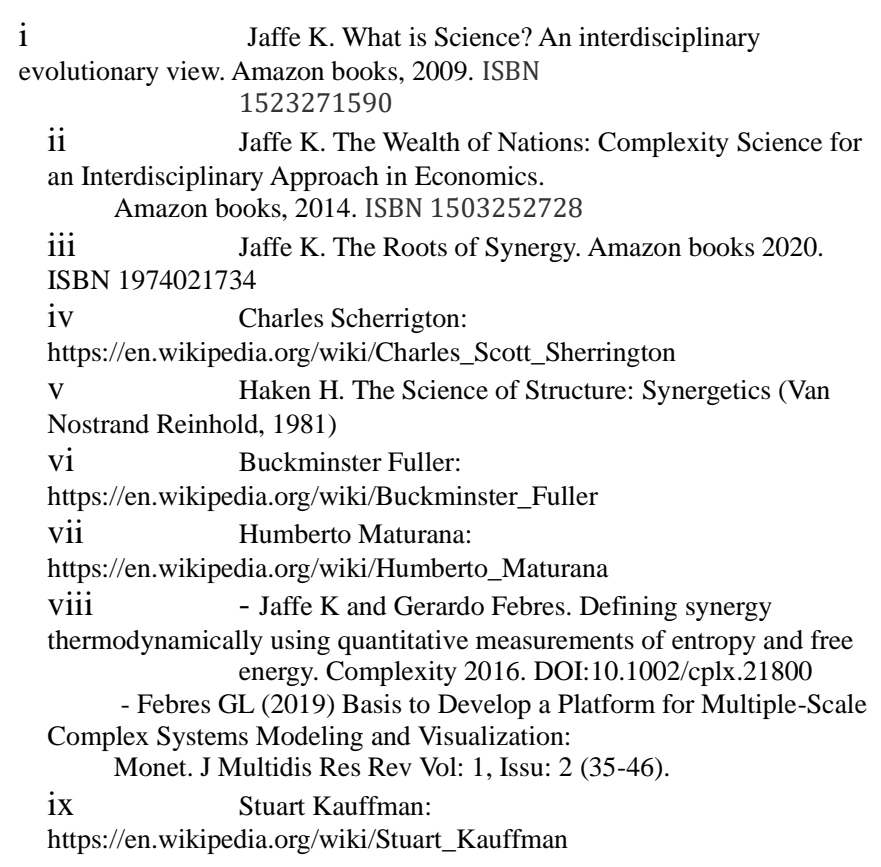

